\title{
TINGKAT PENGETAHUAN REMAJA PUTRI TENTANG MENSTRUASI
}

\author{
Putri Amalia'), Yola Amrullah2) \\ 1 Jurusan Diploma Tiga Kebidanan STIKes Prima Indonesia \\ Email: putriamalia@stikesprimaindonesia.ac.id \\ 2 Jurusan Diploma Tiga Kebidanan STIKes Prima Indonesia
}

\begin{abstract}
Background From the results of 2014 student health research in the city of Bekasi showed that $46 \%$ of students had reproductive health problems, namely menarche age less than 8 years and more than 15 years, irregular menstrual cycles each month, and menstrual disorders both severe abdominal pain, vaginal discharge or itching around the genitals.

The purpose of this study was to describe the level of knowledge of young women about menstruation in the 21 st junior high school in Bekasi.

MethodsThis research is a descriptive research. The number of research samples was 65 respondents. The instrument in this study was a questionnaire. How to collect data using primary data. The dependent variable in this study is the level of adolescent knowledge about menstruation and the independent variables in this study are sources of information, parental roles, nutritional status, social environment and age of menarche. The type of data used in this study is primary dataobtained from the results of a questionnaire that has been filled by student in 21st junior high school Bekasi in 2019. This research method uses primary data collection by filling out the questionnaire. The number of research samples was 65 respondents. The variable in this study is the level of knowledge of young women about menstruation.

The results of the study illustrate the knowledge of adolescents who have good knowledge there are 35 people (53.8\%), 44 people (67.7\%) from non-media information sources, 51 people (78.5\%) in the group of teens whose parents have a role, 52 people (80.0\%) in adolescents whose nutritional status had a normal body weight, 37 people (56.9\%) in adolescents whose social environment was influential, and menarche age <12 years were 54 people (83.1\%).

Conclusion: The knowledge of young women about menstruation in class VII at SMPN 21 Bekasi obtained a good amount of knowledge as many as 35 people (53.8\%).
\end{abstract}

Keywords: Knowledge, source of information, parent's role, nutritional status, social environment and age of menarche.

\section{ABSTRAK}

Latar Belakang: Dari hasil penelitian kesehatan peserta didik tahun 2014 di kota bekasi menunjukan bahwa $46 \%$ siswi memiliki masalah kesehatan reproduksi, yaitu usia menarche kurang dari 8 tahun dan lebih dari 15 tahun, siklus menstruasi yang tidak teratur tiap bulan, serta gangguan menstruasi baik nyeri perut hebat, keputihan maupun gatal disekitar kemaluan.

Tujuan dari penelitian ini adalah untuk mengetahui gambaran tingkat pengetahuan remaja putri tentang menstruasi di SMPN 21 Kota Bekasi. Jenis data yang digunakan dalam penelitian ini adalah data primer yang didapatkan dari hasil kuesioner yang telah diisi oleh siswi SMPN 21 Kota Bekasi tahun 2019.

Metode penelitian ini menggunakan pengumpulan data primer dengan pengisian kuesioner. Jumlah sampel penelitian sebanyak 65 responden. Instrument dalam penelitian ini adalah kuisioner. Variabel dalam penelitian ini adalah tingkat pengetahuan remaja putri tentang menstruasi.

Hasil penelitian gambaran pengetahuan remaja yang memiliki pengetahuan baik ada 35 orang (53.8\%), 44 orang $(67.7 \%)$ dari sumber informasi non media, 51 orang $(78.5 \%)$ pada kelompok remaja yang orang tuanya berperan, 52 orang $(80.0 \%)$ pada remaja yang status gizi memiliki berat badan normal, 37 orang $(56.9 \%)$ pada 
remaja yang lingkungan sosialnya berpengaruh, dan usia menarche yang kurang $<12$ th sebanyak 54 orang $(83.1 \%)$.

Kesimpulan: Pengetahuan remaja putri tentang menstruasi di kelas VII di SMPN 21 Bekasi didapatkan jumlah pengetahuan yang baik sebanyak 35 orang $(53.8 \%)$.

Kata kunci : Pengetahuan, sumber informasi, peran orang tua, status gizi, lingkungan sosial dan usia menarche.

\section{PENDAHULUAN}

Menurut WHO remaja adalah individu yang mengalami pubertas dimana terjadi transisi dari masa kanak-kanak ke masa remaja, masa remaja ditandai dengan adanya perubahan fisik, psikologi dan kematangan organ reproduksi. Pada masa remaja perempuan salah satu tanda primer pubertas adalah terjadinya menarche. Pada saat awal setelah menarche siklus dan pola menstruasi belum sepenuhnya teratur. Masa pubertas dalam kehidupan kita biasanya dimulai saat berumur 8 hingga 10 tahun dan berakhir lebih kurang di usia 15 hingga 16 tahun (WHO, 2015).

Menstruasi adalah proses alamiah yang terjadi pada perempuan. Menstruasi merupakan pendarahan yang teratur dari uterus sebagai tanda bahwa organ kandungan telah berfungsi matang. Umumnya, remaja yang mengalami menarche adalah pada usia 12 tahun sampai 16 tahun. Siklus menstruasi normal terjadi setiap 22-35 hari dengan lamanya menstruasi selama 2-7 hari (Kusmiran, 2012).

Kementrian kesehatan mengupayakan kebersihan menstruasi dengan memberikan tiga usaha kesehatan sekolah (Trias UKS). Upaya tersebut dilakukan agar remaja yang baru mengalami menstruasi dapat memahami pentingnya menjaga kebersihan saat menstruasi, dampak yang terjadi bila tidak menjaga kebersihan saat menstruasi akan rentan terjadi infeksi saluran kencing, infeksi saluran reproduksi dan iritasi pada kulit (Kemenkes RI, 2015).

Menurut WHO 2014 di dunia diperkirakan kelompok remaja berjumlah 1,2 milyar, atau $18 \%$ dari jumlah penduduk dunia di Indonesia, jumlah kelompok usia 10-19 tahun menurut sensus penduduk 2010 sebanyak 43,5 juta atau sekitar $18 \%$ dari jumlah penduduk dan di Yogyakarta sekitar 68,2\% menurut perkiraan badan pusat statistic (BPS), persentase remaja mencapai $24,13 \%$ dengan pertumbuhan tiga kali lipat lebih $(3,24 \%)$ dibandingkan dengan prtumbuhan penduduk

(BPS, 2012), badan kependudukan dan keluarga berencana nasional, penduduk remaja akan berpengaruh pada pengetahuan dari aspek sosial, ekonomi, maupun demografi baik saat ini maupun dimasa yang akan dating (BKKBN, 2015).

Data penelitian kesehatan peserta didik tahun 2014 di kota bekasi menunjukan bahwa 46\% siswi memiliki masalah kesehatan reproduksi, yaitu usia menarche kurang dari 8 tahun dan lebih dari 15 tahun, siklus menstruasi yang tidak teratur tiap bulan, serta gangguan menstruasi baik nyeri perut hebat, keputihan maupun gatal disekitar kemaluan (Dinkes Kota Bekasi, 2014).

\section{METODOLOGI PENELITIAN}

Jenis penelitian yang digunakan adalah metode deskriptif yang bertujuan untuk mengetahui gambaran tingkat pengetahuan remaja putri tentang menstruasi di SMPN 21 Kota Bekasi. Penelitian ini dilaksanakan di SMPN 21 Kota Bekasi. Jenis data yang digunakan dalam penelitian ini adalah data primer yang didapatkan dari hasil kuesioner yang telah diisi oleh siswi SMPN 21 Kota Bekasi tahun 2019. Instrumen yang digunakan oleh penelitian dalam bentuk kuesioner.

Populasi dalam penelitian ini adalah siswi di SMPN 21 Kota Bekasi periode April adalah 186 orang. Jumlah sampel dalam penelitian ini adalah 65 siswi di SMPN 21 Kota Bekasi yang merupakan sebagaian dari populasi. Pengambilan sampel dengan menggunakan rumus slovin. 


\section{HASIL DAN PEMBAHASAN}

Tabel 1 Distribusi Frekuensi Remaja Putri Tentang Menstruasi di SMPN 21 Kota Bekasi

Berdasarkan Pengetahuan, Sumber Informasi, Peran Orang Tua, Status Gizi, Lingkungan Sosial Dan Usia Menarche

\begin{tabular}{lcc}
\hline \multicolumn{1}{c}{ Variable } & $f$ & $\%$ \\
\hline Pengetahuan & & \\
Baik & 35 & $55.8 \%$ \\
Cukup & 22 & $33.8 \%$ \\
Kurang & 8 & $12.3 \%$ \\
\hline
\end{tabular}

Hasil tabel diatas Menunjukan bahwa dari total keseluruhan sampel yaitu 65 Responden, Hasil penelitian gambaran pengetahuan remaja putri yang memiliki pengetahuan baik ada 35 orang
(53.8\%), 22 orang memiliki pengetahuan cukup $(33.8 \%)$, sisanya 8 orang $(12.3 \%)$ memiliki pengetahuan yang kurang.

Tabel 2 Distribusi Frekuensi Remaja Putri Tentang Menstruasi di SMPN 21

Kota Bekasi Berdasarkan Sumber Informasi

\begin{tabular}{lcc}
\hline \multicolumn{1}{c}{ Variable } & $f$ & $\%$ \\
\hline Sumber Informasi & & \\
Non Media & 44 & $66.7 \%$ \\
Media Massa & 12 & $18.5 \%$ \\
Media Elektronik & 9 & $13.8 \%$ \\
\hline
\end{tabular}

Hasil table diatas gambaran pengetahuan remaja putri yang memiliki pengetahuan berdasarkan sumber informasi 44 orang $(67.7 \%)$ dari sumber informasi non media, Sedangkan jumlah responden yang mendapatkan sumber informasi dari Media Massa berjumlah 12 orang $(18.5 \%)$. Sisanya responden yang mendapatkan sumber informasi dari Media Elektronik berjumlah 9 orang $(13.8 \%)$.

\section{Tabel 3 Distribusi Frekuensi Remaja Putri Tentang Menstruasi di SMPN 21 Kota Bekasi Berdasarkan Peran Orang Tua}

\begin{tabular}{lcc}
\hline \multicolumn{1}{c}{ Variable } & $f$ & $\%$ \\
\hline Peran Orang Tua & & \\
Berperan & 51 & $78.5 \%$ \\
Tidak Berperan & 14 & $21.5 \%$ \\
\hline
\end{tabular}

Hasil table diatas gambaran pengetahuan remaja putri yang memiliki pengetahuan berdasarkan peranan orang tua 51 orang $(78.5 \%)$ pada kelompok remaja yang orang tuanya berperan, sedangkan yang tidak berperan memberikan bimbingan tentang menstruasi yaitu berjumlah 14 orang $(21.5 \%)$,

Tabel 4 Distribusi Frekuensi Remaja Putri Tentang Menstruasi di SMPN 21 Kota Bekasi Berdasarkan Status Gizi

\begin{tabular}{lcc}
\hline \multicolumn{1}{c}{ Variable } & $f$ & $\%$ \\
\hline Status Gizi & & \\
Kurang $<18,5$ & 5 & $7.7 \%$ \\
Normal $19-24,5$ & 52 & $80.0 \%$ \\
Lebih $25-29,9$ & 8 & $12.3 \%$ \\
\hline
\end{tabular}


Hasil tabel diatas gambaran pengetahuan remaja putri yang memiliki pengetahuan berdasarkan status gizi berat badannya Normal dari 19-24,5 berjumlah 52 orang $(80.0 \%)$. Sedangkan jumlah berat badannya yang Kurang dari $<18,5$ berjumlah 5 orang $(7.7 \%)$. Sisanya responden yang berat badannya yang Lebih dari $25-29,9$ berjumlah 8 orang $(12.3 \%)$.

Tabel 5 Distribusi Frekuensi Remaja Putri Tentang Menstruasi di SMPN 21 Kota Bekasi Berdasarkan Lingkungan Sosial

\begin{tabular}{lcc}
\hline \multicolumn{1}{c}{ Variable } & $f$ & $\%$ \\
\hline Lingkungan Sosial & & \\
Berpengaruh & 37 & $56.9 \%$ \\
Tidak Berpengaruh & 28 & $43.1 \%$ \\
\hline
\end{tabular}

Hasil tabel diatas gambaran pengetahuan remaja putri yang memiliki pengetahuan berdasarkan lingkungan sosial Berpengaruh terhadap menstruasi yaitu berjumlah 37 orang
(56.9\%). Sedangkan responden yang lingkungan sosialnya Tidak Berpengaruh berjumlah 28 orang $(43.1 \%)$.

\section{Tabel 6 Distribusi Frekuensi Remaja Putri Tentang Menstruasi di SMPN 21 Kota Bekasi Berdasarkan Usia Menarche}

\begin{tabular}{lcc}
\hline \multicolumn{1}{c}{ Variable } & $f$ & $\%$ \\
\hline Usia Menarche & & \\
Usia Menarche $<12$ th & 54 & $83.1 \%$ \\
Usia Menarche $>13-15$ th & 11 & $16.9 \%$ \\
\hline
\end{tabular}

Hasil penelitian gambaran pengetahuan remaja putri yang memiliki pengetahuan berdasarkan usia menarche yang kurang dari $<12$ th berjumlah 54 orang (83.1\%). Sedangkan usia menarche lebih dari 13 - 15 th sebanyak 11 orang $(16.9 \%)$

\section{Analisis Univariat}

Digunakan untuk mendeskripsikan variabel penelitian guna memperoleh gambaran atau karakteristik sebelum dilakukan analisis bivariabel. Hasil dari penelitian ditampilkan dalam bentuk distribusi frekuensi. Dalam penelitian ini jenis datanya adalah data katagorik yang hanya menjelaskan angka/nilai, jumlah dan presentasi masing - masing variable. Analisis univariat dilakukan menggunakan rumus berikut (Notoatmodjo, 2014):

$$
p=\frac{f}{n} \times 100 \%
$$

Keterangan :

$\mathrm{p}:$ Rataan hitungan dalam \% (Presentase)

$\mathrm{f}$ : Jumlah kejadian pada responden

$\mathrm{n}$ : Jumlah seluruh responden

\section{KESIMPULAN}

Dari hasil penelitian dengan 65 responden tentang Tingkat Pengetahuan Remaja Putri tentang Menstruasi di SMPN 21 Kota Bekasi Tahun 2019 dapat disimpulkan sebagai berikut: Pengetahuan remaja putri tentang menstruasi di kelas VII di SMPN 21 Bekasi didapatkan jumlah pengetahuan yang baik sebanyak 35 orang (53.8\%).

\section{SARAN}

Bagi remaja putri diharapkan remaja putri memiliki tingkat pengetahuan yang baik serta menyeluruh mengenai menstruasi, Agar dapat menambah pengetahuan dan wawasan remaja putri tentang menstruasi, sehingga remaja putri bisa berperilaku sehat dalam menangani menstruasi 


\section{DAFTAR PUSTAKA}

Fitri Imelda, 2015, Lebih Dekat Dengan Sistem Reproduksi Wanita, Yogyakarta: Gosyen Publishing

Hasanah, 2014, Jurnal Gambaran Tingkat Pengetahuan Remaja Tentang Menstruasi Pertama

Intan, 2015, Jurnal Faktor-faktor yang Berhubungan Dengan Gangguan Menstruasi

Kumalasari Intan, 2015, Kesehatan Reproduksi, Jakarta : Salemba Medika

Kusmiran Eny, 2014, Kesehatan Reproduksi Remaja dan Wanita, Jakarta : Salemba Medika

Marmi, 2014, Kesehatan Reproduksi, Yogyakarta : Pustaka Pelajar

Maryunani Anik, 2014, Biologi Reproduksi dalam Kebidanan, Jakarta : TIM

Mubarak, 2015, IImu Kesehatan Masyarakat, Jakarta : Salemba Medika
Notoatmodjo, 2018, Kesehatan Masyarakat, Jakarta : Rineka Cipta

Notoatmodjo, 2018, Promosi Kesehatan dan Perilaku Kesehatan, Jakarta : Rineka Cipta Setiyaningrum Erna, 2015, Pelayanan Keluarga Berencana dan Kesehatan Reproduksi, Jakarta : TIM

Walyani Elisabeth, 2015, Kesehatan Reproduksi dan Keluarga Berencana, Yogyakarta : Pustaka Baru Press

https://hellosehat.com/penyakit/anemia/

https://id.m. wikipedia.org/wiki/Pubertas

http://www.depkes.go.id/article/view/17052700001/ manajemen-kebersihan-menstruasi-perludipahami-.html

https://www.alodokter.com/menstruasi https://id.m.wikipedia.org/wiki/Menstrusi 